\title{
Method of the Increasing the Detection of Digital Radiosignals
}

\author{
Barabash Oleg ${ }^{1}$ \\ Laptiev Oleksandr ${ }^{2}$ \\ Svynchuk Olga 3 \\ Openko Pavlo
}

\author{
${ }^{I}$ State University of Telecommunications, Solomenskaya Str., 7, \\ 03110 Kyiv, Ukraine, Email: bar64@ukr.net \\ ${ }^{2}$ State University of Telecommunications, Solomenskaya Str., 7, \\ 03110 Kyiv,Ukraine,Email: alaptev64@ukr.net \\ ${ }^{3}$ State University of Telecommunications, Solomenskaya Str., 7, \\ 03110 Kyiv, Ukraine,Email: 7011990@ukr.net \\ ${ }^{4}$ Ivan Cherniakhovskyi National Defense University of Ukraine, \\ Povitroflotsky Prospect 28, 03049 Kyiv, Ukraine, Email: \\ pavel.openko@ukr.net
}

\begin{abstract}
In the process of detecting and recognizing a digital radio signal, a topical issue is increasing noise immunity. The features of the use of low frequency filters with quadratic and linear response dependence on the input signal are investigated in the article. It is shown that the principle of operation offilters is that the summation process is performed. In this case, the useful signal is summed up coherently and the interference signal is incoherent, ie, the useful signal increases and the interference signal decreases. The filtration process is simulated at different correlation coefficients. This confirmed the possibility of isolating the signal of the means of silent receiving of information by the method of determining the two-dimensional density of the likelihood of interference signal against the background of the common signal. It is proved that the use in the process of signal processing of narrow-banded filters of low frequency allows to increase the noise immunity of the system of detection and recognition of digital radio air signals by $23 \%$.
\end{abstract}

Keywords: noise immunity, filter, mathematical expectation, variance.

\section{INTRODUCTION AND PROBLEM STATEMENT}

A considerable number of publications are devoted to the issue of noise immunity. The technical methods of improving radio efficiency related to noise immunity are considered. However, noise immunity issues are not addressed when probable digital signals are detected. The issue of digital signal recognition is not resolved. From the analysis of modern literature, we can conclude that the problems of noise immunity, which have their own peculiarities in the process of detecting and recognizing digital signal of digital radio broadcasting, are practically not considered.

\section{PROBLEM SOLUTION AND RESULTS}

Almost all methods of noise immunity receive signals based on the principle of signal averaging and interference. This principle is that the summation process is performed. Moreover, the useful signal is summed up coherently, and the noise signal is incoherent. For the purpose of averaging the useful signal and interference, linear systems of two types are used: narrow band filters and low frequency filters. It is possible to optimize low pass filters or narrow band filters.

To consider the issue of interference filtering, let us assume that the narrowband filter itself does not distort the signal that has passed through it. An ideal bandpass filter is a filter with an amplitude-frequency response of the type:

$$
K(\omega)=\left\{\begin{array}{l}
1 \text { if } \quad \omega_{0}-\frac{\Delta \omega}{2} \leq|\omega| \leq \omega_{0}+\frac{\Delta \omega}{2} \\
0 \text { if }]-\infty, \omega_{0}-\frac{\Delta \omega}{2}[U] \omega_{0}+\frac{\Delta \omega}{2}, \infty[
\end{array}\right.
$$

The frequency response of the expression for (1) is the impulse transition characteristic, which will be determined by the expression:

$$
h_{\delta}(t)=\frac{\Delta \omega}{\pi} \cdot \frac{\sin \frac{\Delta \omega t}{2}}{\frac{\Delta \omega t}{2}} \cos \omega_{0} t .
$$

Given that the digital signal is not a clear pulse [8], it is possible to calculate the envelope voltage at the output of an ideal filter when exposed to a rectangular pulse of duration:

$$
x(t)=\left\{\begin{array}{l}
X_{m} \cos \omega_{0} t \text { if } 0 \leq t \leq T \\
0 \text { if }]-\infty, 0[U] T, \infty[
\end{array}\right.
$$

Using the envelope voltage theorem of the narrowband filter, we write the expression for the envelope voltage at the output of the filter:

$$
\begin{gathered}
Y_{m}(t)=\frac{1}{2 \pi} \int_{-\infty}^{\infty} K_{f n}(j \omega) S_{X_{m}}(j \omega) e^{j \omega t} d t . \\
K_{f n}(j \omega)= \begin{cases}1 & \text { if } \quad-\frac{\Delta \omega}{2} \leq|\omega| \leq \frac{\Delta \omega}{2} \\
0 & \text { if }]-\infty, \frac{\Delta \omega}{2}[U] \frac{\Delta \omega}{2}, \infty[\end{cases}
\end{gathered}
$$

Substituting expression (5) into expression (4), we get the expression:

$$
Y_{m}(t)=\frac{X_{m}}{2 \pi}(\operatorname{Si}(\Delta \omega t)-\operatorname{Si}(\Delta \omega(t-T))) .
$$

In fig. 1 dependency graphs of the duration of the influencing rectangular pulse (blue color - pulse duration $\mathrm{T}=1$, red color $-\mathrm{T}=10$, green color $-\mathrm{T}=15$ and black color $\mathrm{T}=20$ ) on the frequency range (filter bandwidth).

The graphs show significant differences between the input rectangular pulse and the output signal. The distortion of the input impulse increases as its duration increases. This distortion of the pulse shape can be characterized by the duration of the envelope of the impulse of the filter output to the duration of 36 


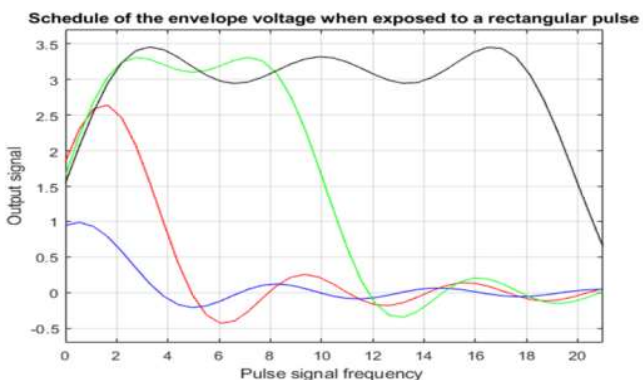

Figure. 1. Graph of the envelope voltage when exposed to a rectangular pulse signal

Research, methods and research techniques, collection and processing data, and for the mathematical and computer models - results of numerical simulations.

\section{CONCLUSIONS}

The peculiarities of the use of low-pass filters to increase the noise immunity of an automated system for detecting and recognizing digital airwaves are investigated. It is shown that the principle of operation of filters is that the summation process is performed. In this case, the useful signal is summed up coherently, and the noise signal is incoherent. That is, when summing up, the useful signal increases and the interference signal decreases.

Taking into account the peculiarities of the digital signal, the signal parameters are defined (mathematical expectation, correlation coefficient, variance, root mean square deviation) and the outputs of linear and quadratic filters at the influence on the input of a rectangular pulse that simulates the signal of modern digital means of silent receiving of information are determined.

The graphs of the envelope voltage at the output of the perfect bandpass filter with the influence on the input of a rectangular pulse (digital signal) of different duration are obtained.

The results of the simulation of the filtering process, with different correlation coefficients, confirmed the possibility of selection of the digital signal by the method of determining the two-dimensional probability density of the signal of interference on the background of the common signal.

It is proved that the use in the process of signal processing of low bandwidth filters of low frequency allows to increase the noise immunity of the system of detection and recognition of digital radio airwaves signals by $23 \%$.

A considerable number of publications are devoted to the issue of noise immunity. Thus, in [1], the technical methods of improving radio efficiency related to noise immunity are considered. The methods of increase of noise protection and noise immunity are considered and the factors that shape them. It is shown that variants of coding of the source of information do not fundamentally affect the stability of radio stations during the action of these interferences. However, noise immunity issues are not addressed when probable digital signals are detected. In [2], the process of noise immunity of a typical detection path composed of sequentially included modules is considered: an ideal bandpass filter, a quadratic detector, and an ideal integrator. However, the issue of the effect of interference on a rectangular signal that is similar to a digital signal is not addressed. In article [3], using the methods of statistical radio engineering, the noise immunity of receiving signals with quadrature amplitude modulation in the presence of noise and harmonic interference is analyzed. In article [4], based on distributed models, a method of bringing voice signals to a single amplitude and time window is proposed. The proposed methods can be used in signal recognition systems. In [5], an optimization model for the measurement of power in circuits was developed on the basis of studies conducted in MATLAB. In [6] investigated the effect of multiray propagation of radio waves on the transmission of audio content through channels with normal and lognormal interference distribution using GSM and WiMAX wireless technologies. In [7], a technique for the interaction of mobile technical objects in the process of data flow transfer under conditions of powerful electromagnetic field is proposed. The work [8] is devoted to increasing the noise immunity of information messages under the conditions of powerful electromagnetic interference by the use of complex signal-code structures. This increases the volume and speed of information transfer. In [9] the results of studies on increasing the signal-tonoise ratio in mobile communication systems are highlighted. This direction is realized through the use of methods of dynamic change of transmitter power, organization of multiple access and dynamic distribution of communication channels. However, the issue of digital signal recognition is not resolved. From the analysis of modern literature, we can conclude that the problems of noise immunity, which have their own peculiarities in the process of detecting and recognizing digital signal of digital radio broadcasting, are practically not considered.

\section{REFERENCES}

[1] Bakiko V.M., Popovich P.V,. Shvaychenko V.B. Viznachennya zavadostiykosti kanalu zv'yazku za vipadkovogo vplivu zavad. Visnyk Nats. tehn. un-tu "HPI" : zb. nauk. pr. . - Kharkiv : NTU "HPI", 2018. № 14 (1290). S. $7-10$

[2] Churyumov G., Tokarev V., Tkachov V., Partyka S. Scenario of Interaction of the Mobile Technical Objects in the Process of Transmission of Data Streams in Conditions of Impacting the Powerful Electromagnetic Field. 2018 IEEE Second International Conference on Data Stream Mining \& Processing (DSMP). 21-25 Aug. 2018. P. 183-186.

[3] Fedorov E., Alrababah H., Nehad A. The distribution for mation method of reference patterns of vocal speech sounds. International Journal of Advanced Trends in Computer Science and Engineering. 2017. Vol. 6 (3), May - June, P. 35 - 39.

[4] Kulikov G.V., Nesterov A.V., Lelyuh A.A. Pomehoustoychivost priema signalov $\mathrm{s}$ kvadraturnoy amplitudnoy manipulyatsiey $\mathrm{v}$ prisutstvii garmonicheskoy pomehi. Zhurnal radioelektroniki, № 11, 2018 [Elektronniy resurs] Rezhym dostupu: https://elibrary.ru/contents.asp?id=36651217 (20.03.2020).

[5] Laptiev O.A., Barabash O.V., Savchenko V.V., Savchenko V.A., Sobchuk V.V. The method of searching for digital means of illegal reception of information in information systems in the working range of Wi-Fi. International Journal of Advanced Research in Science, Engineering and Technology. India. 2019. Vol. 6, Issue 7. P. 10101 10105.

[6] Laptiev O., ShuklinG., Savchenko V., Barabash O., MusienkoA., Haidur $\mathrm{H}$. The Method of Hidden Transmitters Detection based on the Differential Transformation Model.. International Journal of Advanced Trends in Computer Science and Engineering. 2019. Vol. 8, №6, November- December. P. 538 - 542.

[7] Laptiev Oleksander, Savchenko Vitalii, Syrotenko Anatolii, Shchypanskyi Pavlo, Matsko Oleksander, International Journal of Innovative Technology and Exploring Engineering (IJITEE) Volume-9 Issue-4, February 2020. Scopus Indexed - ISSN 2278 - 3075. P. $2114-$ 2119.

[8] Parkhomenko A.N., Shotskyi B.I. Pereshkodostiikist typovoho traktu pry vyiavlenni syhnaliv z fluktuatsiinoiu amplitudoiu. Mizhnarodnii naukovo-tekhnichnyi zhurnal. [Elektronnyi resurs] Rezhym dostupu: http://radio.kpi.ua/article/view/S002134701982040219 (14.11.2019).

[9] Serkov O. Breslavets V., Tolkachov M., Kravets V. Method of coding information distributed by wireless communication lines under conditions of interference. Advanced Information Systems. 2018. Vol. 2, No. 2. P. $145-148$. 